\title{
Influence of Dacus Oleae infestation on flavor of oils, extracted from attacked olive fruits, by HPLC and HRGC analyses of volatile compounds
}

\author{
Por F. Angerosa, L. Di Giacinto and M. Solinas \\ Istituto Sperimentale per la Elaiotecnica. \\ Via Cesare Battisti, 198. 65100 PESCARA (Italia)
}

\section{RESUMEN}

Influencia de la infestación por Dacus Oleae sobre el flavor de aceites, extraídos de aceitunas atacadas, por análisis HPLC y HRGC de compuestos volátiles.

Los autores han examinado la influencia de la infestación por Dacus Oleae sobre el aroma de aceites obtenidos de aceitunas de las variedades Coratina y Nebbio en diferentes estados de ataque.

Los resultados obtenidos indicaron un empeoramiento de los niveles de calidad de los aceites obtenidos a medida que se incrementaba el porcentaje de aceitunas infestadas; mostrando una gran disminución de las sustancias fenólicas y altos contenidos tanto de alcoholes volátiles como de aldehídos, con una sensación desagradable.

De particular interés fue la relación hexanal/alcoholes volátiles totales, la cual ha sido bien correlacionada con la extensión de la infestación lo que permitiria establecer de una manera objetiva, si y cuantas de las aceitunas de las cuales se ha extraido, han sufrido ataque por Dacus.

PALABRAS-CLAVE: Aceite - Componentes volátiles (determinación) - Dacus Oleae - Flavor - Infestación (influencia de).

\section{SUMMARY}

Influence of Dacus Oleae infestation on flavor of oils, extracted from attacked olive fruits, by HPLC and HRGC analyses of volatile compounds.

The authors have examined the influence of the Dacus Oleae infestation on the aroma of the oils obtained from olives of Coratina and Nebbio varieties at different levels of attack.

The results obtained indicated a worsening of the qualitative level of the oils obtained from increasing percentages of infested olives; these were found to have a great decrease of phenolic substances and higher contents of both volatile alcohols and aldehydes with an unpleasant sensation.

Of particular interest was hexanal/total volatile alcohols ratio, in which having been well correlated with the extent of infestation, would permit one to establish in an objective manner, if and how much the olives from which an oil has been extracted have suffered a Dacus attack.

KEY-WORDS: Dacus Oleae - Flavor - Infestation (influence of) - Oil Volatile components (determination).

\section{INTRODUCTION}

The defects of virgin oil, organoleptically perceptible, are ascribable essentially to the bad sanitary conditions or to the bad conservation of the olives at the moment of the grinding or to the oxiding processes which the oil comes up against during the storage.

In previous research (1) significant correlation has already been evidenced between the organoleptic evaluations determined by way of the Panel test in accordance with the C.O.I. method (2) and some analytical determinations that are able to define the "flavour" of the oils.

Furthermore, a study has been done on the influence on the aroma of the resulting oils, of the oxiding phenomenon of the oils, as well as that of the storage of the olives before grinding, with results that have allowed quantification of the rancid defect as well as that of fustiness (3-6).

Always focusing on the characteristics of defects, having been the 90-91 campaign afflicted by a Dacus attack of notable proportions, it was thought of studying that which was induced on olive oil by the infestation of $D$. oleae.

It is well-known, in fact, that in consequence of the Dacus infestation, in spite of a major yield of oil as a result of a greater synthesis of lipids with respect to that verified in healthy olives (6), the oil production is greatly limited by the establishment of an excessive spontaneous falling of the fruits.

Moreover the resulting oils are penalized due to the more elevated values of free acidity and the number of peroxides and the spectrophotometric absorption values in the U.V. (6-8).

Montedoro and Col. (9) have deepened the study on the effects of the $D$. oleae attack on the oil qualitative characteristics effecting the analysis of the phenolic constituents and of those volatile, verifying that the presence of $D$. oleae modifies the composition of the mentioned substances and interferes negatively also on the organoleptic characteristics and on their stability in time.

\section{EXPERIMENTAL SECTION}

For the purpose of better quantifying the influence that the Dacus infestation seemed to have on the flavour of the oils, two varieties of olives, Coratina and Nebbio 
respectively, cultivated in Abruzzo, were browsingly picked on about the fifteenth of november of the 90-91 campaign.

In consideration of the fact that the damage caused to the fruit increases with the advancing development of the larva internally of the same and that in the same period there coexists infested olives in which the larval development finds itself in different stages, there was isolated by way of attentive olive sorting that, indicating the characteristic way out hole caused by the olive fly, they had surely suffered prominent damage.

Unfortunately during the selection of Nebbio variety olives, lasting two days, the high temperatures evidenced in that period brought about the fusty phenomenon to the olives, greatly more apparent on those attacked by the fly.

The olives that indicated the way out hole, as mentioned above, were then mixed in the proportion of 25 , 50,75 and $100 \%$ of the healthy olives -that constituted the reference- to form the samples to subject to the extraction of oil; particular care was taken in an attempt to try and keep the sample homogeneous, from the point of view of the "state of ripening" taking as a point of reference the uniformity of the colour of the fruits whether healthy or infested.

The sample olives thus formed were immediately washed, deleafed and ground with a hammer mill; the resulting paste was cold kneaded for about $30^{\circ}$ and thus the oils extracted for emergence with basket centrifuge.

On those the following analyses were carried out: organoleptic characteristic evaluation using Panel test method; acidity; number of peroxides; Kreis reaction; U.V. spectrophotometry; HRGC of the volatile substances at $37^{\circ} \mathrm{C}$; HPLC of the volatile carbonyl compounds and alcohols; HRGC of the phenolic substances in accordance with the mode described in previous works (10), (5), (11), (12).

\section{RESULTS AND DISCUSSION}

\subsection{Panel test}

Tab. I gives the evaluations of the Panel of 8 oil tasters of the Institute. Next to every evaluation it is specified the estimated range for the population mean calculated as \pm $s_{x} t / \sqrt{n}$ for the confidence coefficient of $95 \%$, in which:

$s_{x}$ is the sample (or $n-1$ weighted) standard deviation, $n$ is the number of the tasters and $t$ (Student's $t$ ) is equal to 2.365 for the degrees of freedom number equal to seven for the confidence coefficient of $95 \%$. The mentionated evaluations clearly show as the Panel has perceived, even if slight, a significant qualitative worsening of the oils obtained from olives at an increasing percentage of infestation in comparison to those obtained from healthy olives. Moreover for the Nebbio variety, the sensorial valuations show an influence also by the presence of fustiness, as perceived also by the group of oil tasters from the sample obtained with the $50 \%$ infested olives.

Table I

Organoleptic evaluation, free acidity, peroxides number, Kreis reaction and U.V. specific absorption values of the oils obtained from Coratina and Nebbio varieties at different percentage of attacked olives.

\begin{tabular}{|c|c|c|c|c|c|c|c|c|}
\hline Variety & $\begin{array}{c}\text { Attack } \\
\text { degree \% }\end{array}$ & $\begin{array}{l}\text { Organoleptic } \\
\text { evaluation } \\
\bar{X} \pm \frac{S}{\sqrt{n}}^{t}\end{array}$ & $\begin{array}{l}\text { Free acidity } \\
\text { as oleic ac. } \%\end{array}$ & $\begin{array}{c}\text { Peroxides } \\
\text { number } \\
\text { (meq } \mathrm{O}_{2} / \mathrm{Kg} \text { ) }\end{array}$ & $\begin{array}{l}\text { Kreis } \\
\text { reaction }\end{array}$ & $\mathrm{K}_{232}$ & $\mathrm{~K}_{270}$ & $\Delta K$ \\
\hline Coratina & $0 \%$ & $7,0 \pm 0,3$ & 0,31 & 3,0 & neg. & 1,49 & 0,095 & $-0,002$ \\
\hline Coratina & $25 \%$ & $7,0 \pm 0,3$ & 0,33 & 7,0 & neg. & 1,58 & 0,107 & $-0,002$ \\
\hline Coratina & $50 \%$ & $6,5 \pm 0,3$ & 0,34 & 8,0 & neg. & 1,66 & 0,114 & $-0,002$ \\
\hline Coratina & $75 \%$ & $6,4 \pm 0,2$ & 0,56 & 11,5 & neg. & 1,60 & 0,120 & $-0,001$ \\
\hline Coratina & $100 \%$ & $6,2 \pm 0,2$ & 0,80 & 12,3 & neg. & 1,95 & 0,130 & $+0,001$ \\
\hline Nebbio & $0 \%$ & $6,9 \pm 0,2$ & 0,40 & 3,8 & neg. & 1,54 & 0,098 & $-0,002$ \\
\hline Nebbio & $25 \%$ & $6,6 \pm 0,2$ & 0,50 & 4,9 & neg. & 1,67 & 0,107 & $-0,002$ \\
\hline Nebbio & $50 \%$ & $6,4 \pm 0,4$ & 0,57 & 6,1 & neg. & 1,71 & 0,133 & $-0,002$ \\
\hline Nebbio & $75 \%$ & $6,0 \pm 0,3$ & 0,94 & 9,3 & neg. & 1,76 & 0,143 & 0,000 \\
\hline Nebbio & $100 \%$ & $5,7 \pm 0,2$ & 1,15 & 12,0 & neg. & 1,88 & 0,149 & $+0,002$ \\
\hline
\end{tabular}

3.2. Free acidity, number of peroxides, U.V. spectrophotometry.

In analysing the data shown in Tab. I it was found that the free acidity values and those of the number of peroxides increase with the increasing infested olives percentage in accordance with that indicated in the literature (6-8); yet the increase in acidity is not such as to be able to determine the commercial declassing of the oils analysed, with the exception of the Nebbio sample with $100 \%$ infested olives.

The U.V. specific absorption values too increase pro- 
gressively with the extent of the infestation, confirming that the oxidation state of the examined oils is influenced by the Dacus attack.

\subsection{Volatile compounds}

Fig. 1 represents the chromatograms of the volatile substances of the oils extracted from the Coratina variety olives at differing infestation percentages.
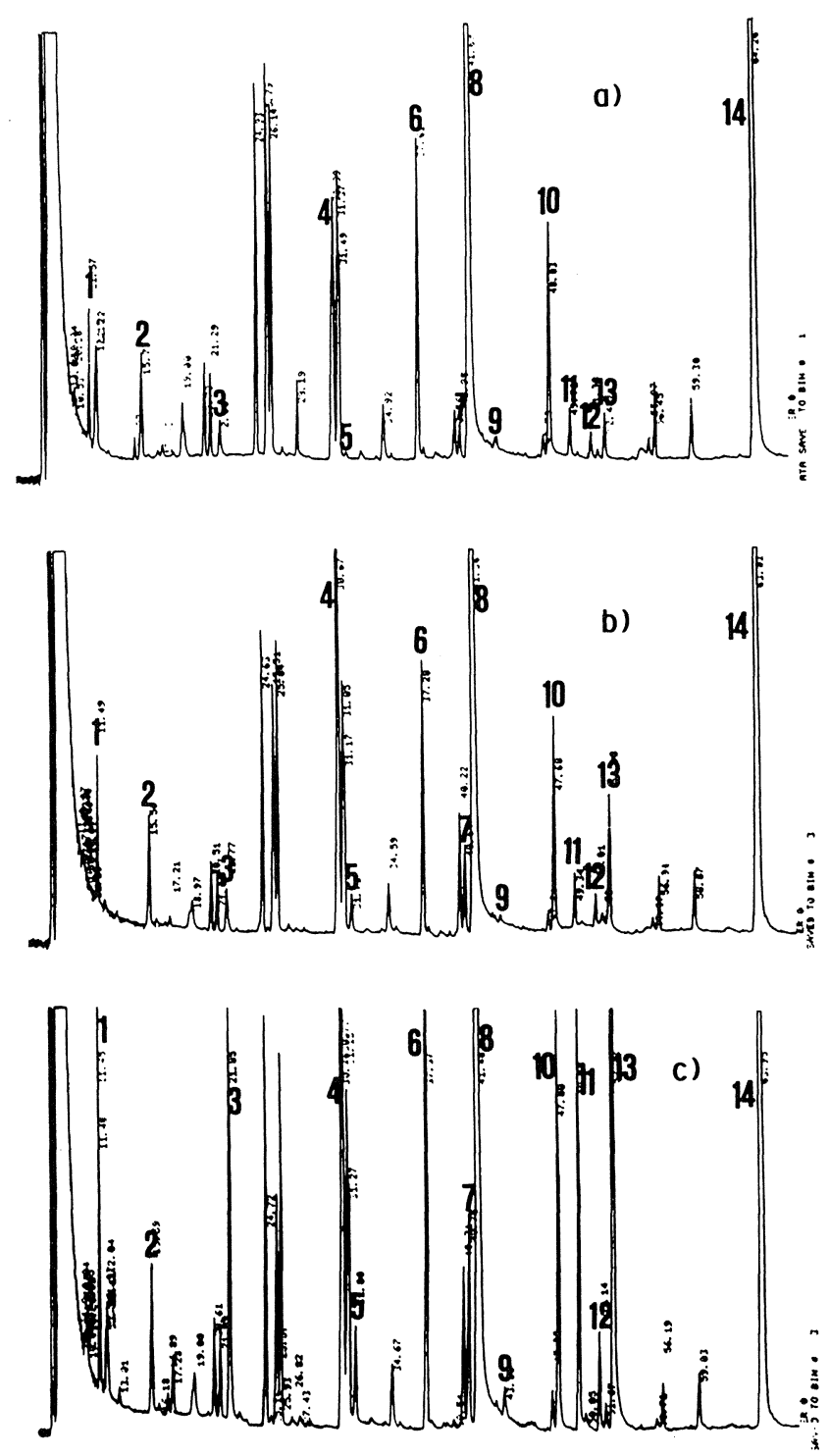

Figure 1

Aroma HRGC analysis of the oils obtained from Coratina variety at different percentage of attacked olives.

a) from $0 \%$ attacked olives; b) from $50 \%$ attacked olives; c) from $100 \%$ attacked olives.

Peaks: $n .1$ = octane; $n .2=$ ethyl acetate; $n .3=3$-pentanone + compound still not identified; $n .4=$ hexanal + compound still not identified; $n .5=$ iso butyl alcohol; $n .6=1$-penten-3-ol; $n .7=$ iso amyl alcohol; $n .8=2$-hexenal; $\mathrm{n} .9=$ amyl alcohol; $\mathrm{n} .10=2$-penten-1-ol; $\mathrm{n} .11=$ hexanol; $\mathrm{n} .12=3$-hexen1-ol; n.13 = trans-2-hexen-1-ol; n.14 = nonanol (internal standard).
From the numerous peaks presented in the chromatogram, only those that, apart from being quantitatively appreciable, indicated for both varieties well defined trends in function with the increasing quantity of attacked olives, were considered.

Tab. II shows the contents expressed in $\mathrm{mg}$ of 1 nonanol per $\mathrm{Kg}$ of oil, of the 13 peaks considered significant.

The analysis of the data in the table indicates that some of these, specifically the peaks nr. 1, 2, 3, 4, 11, 12 and 13 increase linearly by the same amount in both the varieties with the increasing quantity of the attacked olives. These peaks were identified by mass spectrometry (13) as: n-octane, ethyl acetate, 3-pentanone, hexanal, 1hexanol, 3-hexen-1-ol, trans-2-hexen-1-ol. Nevertheless the peaks nr. 3 and 4 , under the gaschromatographical conditions adopted, show themselves to be made up of more substances, only partially separable in the more favourable cases; the identification of these substances, therefore, is related to their complete resolution.

The remaining peaks $\mathrm{nr} .5,6,7,8,9,10$ corresponding (13) respectively to isobutyl alcohol, 1-penten-3-ol, isoamyl alcohol, 2-hexenal, amyl alcohol and 2-penten-1-ol, also increase linearly with the percentage of infested olives, but in a different manner for the two varieties.

In particular the increase of isoamyl alcohol, which in a previous work resulted linearly proportional to the intensity of fustiness (5), leads one to suppose that $D$. oleae attacked olives suffer, once picked of the tree, those typical fermentation processes of fustiness, more rapidly than healthy olives. This phenomenon was more relevant for the Nebbio variety olives due to the sustained high temperatures registred during the time between the picking and the grinding.

In effect, as has already been referred to, the testing cards for this variety put into evidence that the members of the Panel had felt the fusty defect beginning with the third sample, while the Coratina variety is characterized by an absence in perception of the defect confirmed by the way in which the isoamyl alcohol has always an inferior value to the threshold value found in the abovementioned work (5).

\subsection{Carbonyl compounds}

Fig. 2 represents the chromatograms relative to the volatile carbonyl compounds of the oils obtained from Coratina variety at differing percentages of infestation. The contents, expressed in $\mathrm{mg}$ of undecanal per $\mathrm{Kg}$ of oil, are shown in Tab. III. 
Table II

Content, as 1-nonanol ppm, of some volatile compounds of the oils obtained from Coratina and Nebbio varieties at different percentage of attacked olives. Such compounds are identified with the same peak numbers of those in Fig. 1

\begin{tabular}{lrrrrrrrrrrrrrr}
\hline Variety & $\begin{array}{c}\text { Attack } \\
\text { degree } \%\end{array}$ & $\mathbf{1}$ & $\mathbf{2}$ & $\mathbf{3}$ & $\mathbf{4}$ & $\mathbf{5}$ & $\mathbf{6}$ & $\mathbf{7}$ & $\mathbf{8}$ & $\mathbf{9}$ & $\mathbf{1 0}$ & $\mathbf{1 1}$ & $\mathbf{1 2}$ & $\mathbf{1 3}$ \\
\hline Coratina & $0 \%$ & 3,6 & 4,7 & 1,4 & 20,1 & 0,3 & 14,2 & 1,1 & 525,6 & 0,9 & 13,7 & 2,8 & 1,7 & 2,8 \\
Coratina & $25 \%$ & 5,3 & 5,9 & 2,7 & 35,3 & 1,0 & 18,6 & 2,9 & 646,7 & 0,9 & 16,1 & 4,7 & 2,4 & 16,2 \\
Coratina & $50 \%$ & 7,9 & 6,9 & 4,4 & 49,5 & 2,3 & 23,6 & 5,9 & 824,1 & 1,3 & 18,0 & 7,1 & 2,5 & 26,9 \\
Coratina & $75 \%$ & 12,1 & 8,5 & 5,7 & 58,5 & 4,7 & 28,0 & 10,0 & 921,3 & 1,4 & 20,6 & 7,7 & 3,2 & 37,1 \\
Coratina & $100 \%$ & 14,0 & 8,3 & 10,8 & 73,0 & 5,5 & 32,8 & 12,8 & $1.034,2$ & 1,4 & 22,5 & 9,7 & 4,8 & 49,6 \\
Nebbio & $0 \%$ & 6,0 & 12,5 & 3,5 & 28,1 & 3,5 & 10,4 & 7,0 & 116,5 & 1,0 & 9,6 & 6,4 & 18,5 & 2,0 \\
Nebbio & $25 \%$ & 8,7 & 15,9 & 7,3 & 40,2 & 6,5 & 14,2 & 13,9 & 121,9 & 1,3 & 10,4 & 7,8 & 25,4 & 4,8 \\
Nebbio & $50 \%$ & 11,1 & 16,8 & 10,5 & 56,1 & 14,0 & 14,8 & 23,5 & 126,2 & 1,6 & 10,9 & 10,9 & 36,0 & 13,9 \\
Nebbio & $75 \%$ & 13,8 & 18,6 & 15,0 & 65,9 & 20,1 & 15,3 & 37,2 & 126,3 & 2,2 & 11,1 & 13,9 & 44,0 & 27,0 \\
Nebbio & $100 \%$ & 21,0 & 19,0 & 17,8 & 89,0 & 26,1 & 17,8 & 44,8 & 140,4 & 2,8 & 12,5 & 15,8 & 51,9 & 34,9 \\
\hline
\end{tabular}

Table III

Content, as undecanal ppm, of volatile carbonyl compounds of the oils obtained from Coratina and Nebbio varieties at different percentage of attacked olives. Such compounds are identified with the same peak numbers of those in Fig. 2

\begin{tabular}{|c|c|c|c|c|c|c|c|c|c|c|c|c|c|c|c|c|c|}
\hline $\begin{array}{l}\text { Attack } \\
\text { degree \% }\end{array}$ & 1 & 2 & 3 & 4 & 5 & 6 & 7 & 8 & 9 & 10 & 11 & 12 & 13 & 14 & 15 & $\begin{array}{c}\text { Total } \\
\text { carbonyl } \\
\text { compounds }\end{array}$ & $\frac{\text { 2-hexenal }}{\text { hexanal }}$ \\
\hline $0 \%$ & 8,0 & 21,1 & 34,8 & 159,6 & 8,0 & 270,2 & $24.235,6$ & 529,4 & 6,7 & 15,3 & 5,0 & 21,5 & - & 21,7 & - & $25.316,9$ & 945,8 \\
\hline $25 \%$ & 24,2 & 20,2 & 21,5 & 128,6 & 9,0 & 290,9 & $27.103,3$ & $1.134,8$ & 18,4 & 26,0 & 19,0 & 31,0 & - & 25,7 & - & $28.852,6$ & $6 \quad 23,9$ \\
\hline $50 \%$ & 31,4 & 20,1 & 15,3 & 73,5 & 10,0 & 440,9 & $35.054,6$ & $1.707,6$ & 20,0 & 31,0 & 10,0 & 13,7 & - & 26,1 & - & $37.454,2$ & 220,5 \\
\hline $75 \%$ & 40,9 & 10,9 & 10,9 & 99,9 & 27,6 & 489,5 & $38.936,6$ & $2.522,0$ & 25,0 & 55,6 & 9,2 & 19,7 & - & 41,9 & - & $42.289,7$ & $\begin{array}{ll}7 & 15,4\end{array}$ \\
\hline $100 \%$ & 44,6 & 10,7 & 7,0 & 119,6 & 45,3 & 587,9 & $46.227,7$ & $3.964,0$ & 26,8 & 66,2 & 10,7 & 25,9 & - & 65,9 & - & $51.202,3$ & $\begin{array}{ll}3 & 11,7\end{array}$ \\
\hline $0 \%$ & $\operatorname{tr}$ & 38,2 & 71,2 & 176,9 & 52,3 & 414,0 & $4.568,4$ & 668,4 & 475,9 & 38,0 & 2,2 & 12,7 & 10,2 & 361,4 & 42,7 & $6.933,5$ & 6,8 \\
\hline $25 \%$ & 2,0 & 34,9 & 76,9 & 163,2 & 64,5 & 477,2 & $4.844,9$ & $1.083,6$ & 466,0 & 56,7 & 3,1 & 13,0 & 17,9 & 314,5 & 46,2 & $7.664,6$ & 4,5 \\
\hline $50 \%$ & 7,1 & 29,4 & 31,6 & 148,9 & 73,4 & 573,8 & $4.997,1$ & $1.692,7$ & 303,8 & 42,6 & 8,4 & 16,8 & 12,6 & 194,6 & 44,2 & $8.177,0$ & 3,0 \\
\hline $75 \%$ & 10,1 & 26,2 & 12,5 & 48,0 & 87,8 & 216,4 & $5.007,8$ & $2.175,8$ & 283,5 & 59,6 & 12,7 & 30,1 & 5,5 & 88,2 & 23,0 & $8.087,2$ & 2,3 \\
\hline $100 \%$ & 9,9 & 24,9 & 5,2 & 24,9 & 113,3 & 503,1 & $5.913,9$ & $3.248,8$ & 267,5 & 72,9 & 26,2 & 36,9 & $\operatorname{tr}$ & 80,8 & 8,4 & $10.327,7$ & 1,8 \\
\hline
\end{tabular}



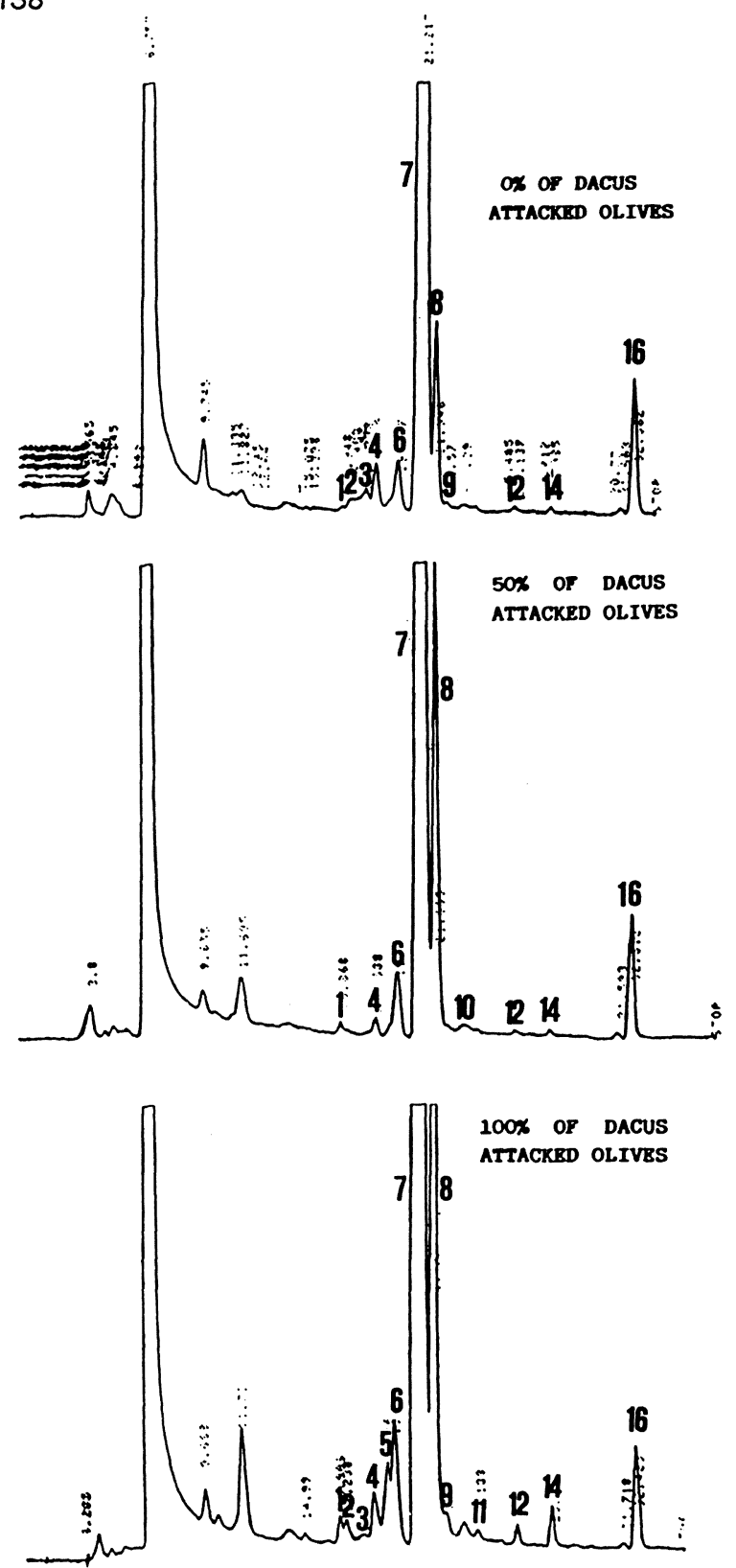

Figure 2

HPLC analysis of dinitrophenylhydrazone derivatives of $37^{\circ} \mathrm{C}$ volatile carbonyl compounds of the oils obtained from Coratina variety at different percentage of attacked olives.

Peaks: $n .1=$ butyraldehyde $n .2=$ unidentified; $n .3=$ unidentified; $n .4=2$ pentenal; $n .5=$ valeraldehyde; $n .6=$ unidentified; $n .7=2$-hexenal; $n .8=$ hexanal; $n .9=$ unidentified; $n .10=2$-heptenal; $n .11=$ heptanal; $n .12=$

octanal; $n .13=2$-nonenal; $n .14=$ nonanal; $n \cdot 15=$ decanal; $n \cdot 16=$ undecanal (internal standard).

Examining the table, the thing that immediately comes to the fore is the increase in content of the trans-2-hexenal due to the Dacus infestation (8), more remarkable for the Coratina variety and more contained for the Nebbio. In effect for this last variety, the fusty defect, that accomplied its sampling, has as a consequence the reduction of 2hexenal and this decrease goes to balance the increase of the same consequence to the attack of the fly (5).

It is well-known how the aldehydes represent the greater part of volatile components $(11,14,15)$ and also how the trans-2-hexenal constitutes about $80-90 \%$ of the carbonyl compounds in the good quality oils; neverthe- less this aldehyde, contained naturally in the fruit, possessing its own pleasant aroma, is directly related to the oil quality.

From an examination of the 2-hexenal contents, it would seem therefore that the oil extracted at greater percentages of infestation are therefore of better quality with respect to that of the reference oil.

Yet, the Panel of oil tasters do not verify this improvement in quality and more than that they report a slight but significant worsening of the qualitative level of oils of the last samples. Really the data shown in Tab. III put into evidence also a sensitive increase in the total carbonyl compounds, deriving from the already mentioned increase of 2-hexenal, as well as the increases suffered by majority of the other carbonyl substances of which only two (peaks nr. 6 and 9) with a presumably pleasant sensation and the others (butyraldehyde, valeraldehyde, hexanal, 2-heptenal, heptanal, octanal) notably unpleasant. Of the latter, particular attention needs to be given to hexanal that exhibits, compared to the reference sample, an increase of about five times in the oils coming from completely infested olives. Moreover, the quantities of hexanal, comparable in both the varieties, suffer the same increase with the extent of infestation, resulting in a good correlation in accordance with the straight of regression illustrated in Fig. 3.

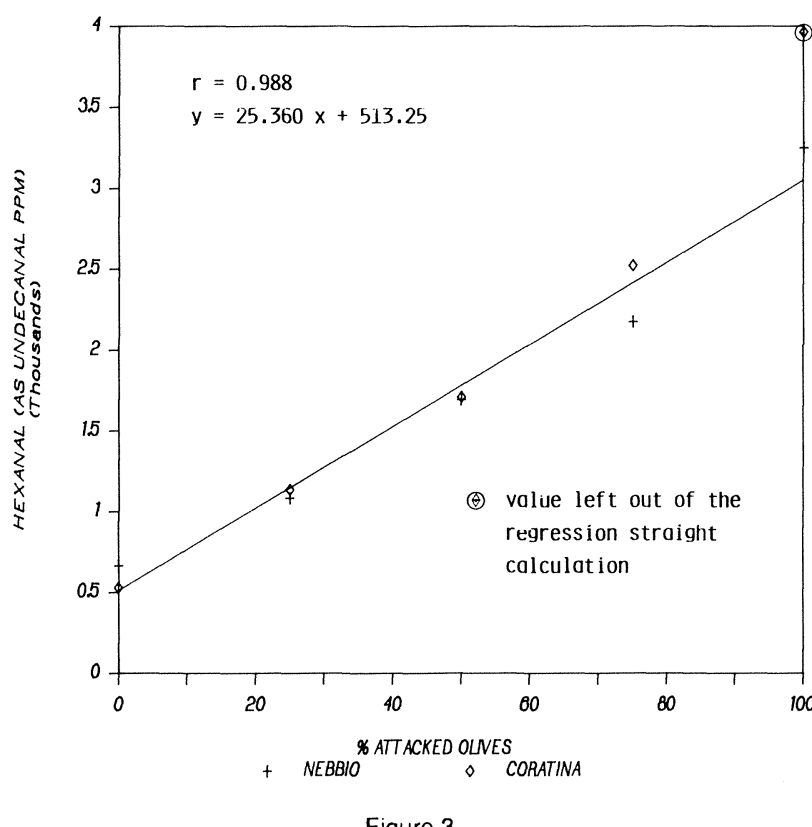

Regression straight relative to the correlation between hexanal quantities and infestation extent for the oils obtained from both the examined varieties.

In relation to what has already been referred to, the quality of an oil will therefore be better identified from the ratio between the carbonyl substances with a pleasant sensation and those with an unpleasant sensation; for this purpose the ratio 2 -hexenal/hexanal is indicative. The values of this ratio, shown in Tab. III diminishe progressively, with the same trend, in both the varieties, in linear relation to the infestation extent implicating a lower quality of oils obtained from olives attacked by the Dacus. 


\subsection{Volatile alcohols}

In Fig. 4 appear the chromatograms of volatile alcohols of the samples obtained from the Coratina variety olives, at different infestation extent, while Tab. IV shows the quantity of the same in $\mathrm{mg}$ of 1 -nonanol per $\mathrm{Kg}$ of oil for both the examined varieties.

Table IV

Content, as 1-octanol ppm, of volatile alcohols of the oils obtained from Coratina and Nebbio varieties at different percentage of attacked olives. Such compounds are identified with the same peak numbers of those in Fig. 4.

\begin{tabular}{lrlllllllllllllllll}
\hline Variety & $\begin{array}{c}\text { Attack } \\
\text { degree } \%\end{array}$ & $\mathbf{1}$ & $\mathbf{2}$ & $\mathbf{3}$ & $\mathbf{4}$ & $\mathbf{5}$ & $\mathbf{6}$ & $\mathbf{7}$ & $\mathbf{8}$ & $\mathbf{9}$ & $\mathbf{1 0}$ & $\mathbf{1 1}$ & $\mathbf{1 2}$ & $\mathbf{1 3}$ & $\mathbf{1 4}$ & $\begin{array}{r}\mathbf{1 5} \\
\mathbf{1 6}\end{array}$ & $\begin{array}{r}\text { Total } \\
\text { volatile } \\
\text { alcohols }\end{array}$ \\
\hline Coratina & $0 \%$ & 2,2 & - & 0,1 & - & $\operatorname{tr}$ & - & 8,7 & - & 0,3 & 0,6 & 0,8 & 2,2 & 0,9 & 1,9 & - & - & 17,7 \\
Coratina & $25 \%$ & 3,1 & $\operatorname{tr}$ & $\operatorname{tr}$ & $\operatorname{tr}$ & 0,1 & 0,3 & 9,7 & - & 1,2 & 0,8 & 2,3 & 8,8 & 0,8 & 6,2 & - & - & 33,3 \\
Coratina & $50 \%$ & 3,9 & 0,3 & - & - & 0,2 & $\operatorname{tr}$ & 6,3 & 0,2 & 1,9 & 0,6 & 0,7 & 16,6 & 0,2 & 11,4 & $\operatorname{tr}$ & - & 42,3 \\
Coratina & $75 \%$ & 4,6 & $\operatorname{tr}$ & - & $\operatorname{tr}$ & 0,2 & $\operatorname{tr}$ & 9,0 & $\operatorname{tr}$ & 3,2 & 0,7 & 0,7 & 25,2 & 1,3 & 11,6 & $\operatorname{tr}$ & - & 56,5 \\
Coratina & $100 \%$ & 6,6 & 0,6 & - & 0,2 & 0,2 & $\operatorname{tr}$ & 8,8 & 0,1 & 3,6 & 1,0 & 1,3 & 31,8 & $\operatorname{tr}$ & 14,2 & $\operatorname{tr}$ & - & 68,4 \\
Nebbio & $0 \%$ & 1,3 & 0,4 & $\operatorname{tr}$ & 0,5 & 0,5 & 2,4 & 3,0 & 1,1 & 2,2 & 2,4 & 0,8 & $\operatorname{tr}$ & 2,1 & 4,1 & 4,7 & - & 25,5 \\
Nebbio & $25 \%$ & 1,1 & $\operatorname{tr}$ & $\operatorname{tr}$ & 3,0 & 0,9 & 0,3 & 4,1 & 0,6 & 3,1 & 7,3 & 0,3 & 1,6 & 1,5 & 5,0 & 4,2 & - & 33,0 \\
Nebbio & $50 \%$ & 0,8 & 0,9 & 1,0 & 0,7 & 1,3 & 1,6 & 4,2 & 0,5 & 6,8 & 8,3 & 0,5 & 5,8 & 1,2 & 6,2 & 1,9 & 1,6 & 43,3 \\
Nebbio & $75 \%$ & 0,6 & $\operatorname{tr}$ & 0,8 & $\operatorname{tr}$ & 1,5 & 0,2 & 4,2 & $\operatorname{tr}$ & 10,4 & 11,1 & 0,5 & 7,3 & 0,9 & 8,4 & 1,0 & 0,4 & 47,3 \\
Nebbio & $100 \%$ & 1,0 & 0,3 & 0,5 & $\operatorname{tr}$ & 2,0 & 0,3 & 4,3 & $\operatorname{tr}$ & 17,0 & 13,5 & 0,4 & 8,2 & 1,9 & 11,1 & 4,4 & $\operatorname{tr}$ & 64,9 \\
\hline
\end{tabular}

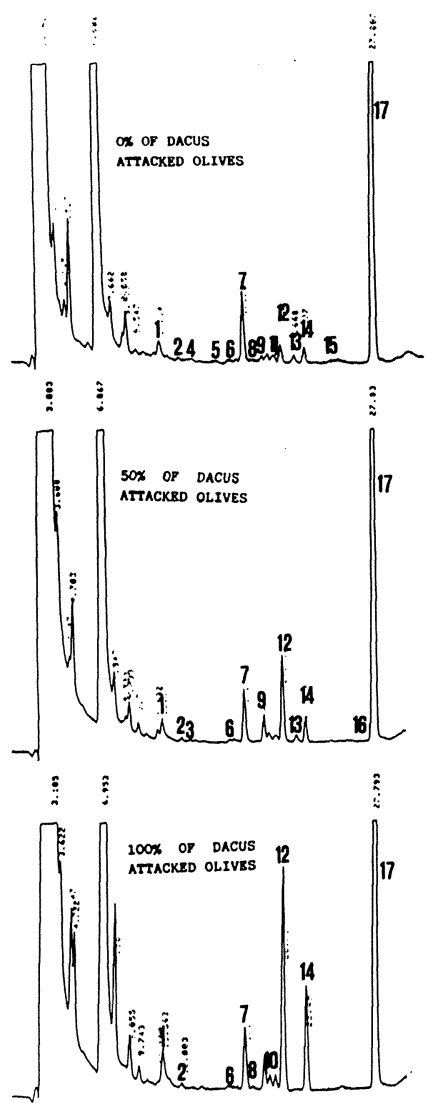

Figure 4

HPLC analysis of dinitrobenzoate derivatives of $37^{\circ} \mathrm{C}$ volatile alcohols of the oils obtained from Coratina variety at different percentage of attacked olives. Peaks: $n .1=$ ethyl alcohol; $n .2=$ unidentified; $n .3=$ unidentified; $n .4=$ unidentified; $n .5=$ unidentified; $n .6=$ iso butyl alcohol; $n .7=2$-penten-1ol; $n .8=$ unidentified; $n .9=$ iso amyl alcohol; $n .10=$ amyl alcohol; $n .11=$ unidentified; $n .12=2$-hexen-1-ol + compound still not identified; $n .13=$ unidentified; $n .14=1$-hexanol; $n .15=$ unidentified; $n .16=$ unidentified; n.17 = 1-octanol (internal standard)
The analysis of the data obtained puts into evidence that the majority of the alcohols increases with the extent of infestation and the major increases are attributable to isoamyl alcohol, 2-hexen-1-ol + compound still not identified and 1-hexanol; ethanol, isobutyl alcohol, amyl alcohol and 2-penten-1-ol increase only marginally. All these substances indicate the same trend already recorded in the GLC of the aroma.

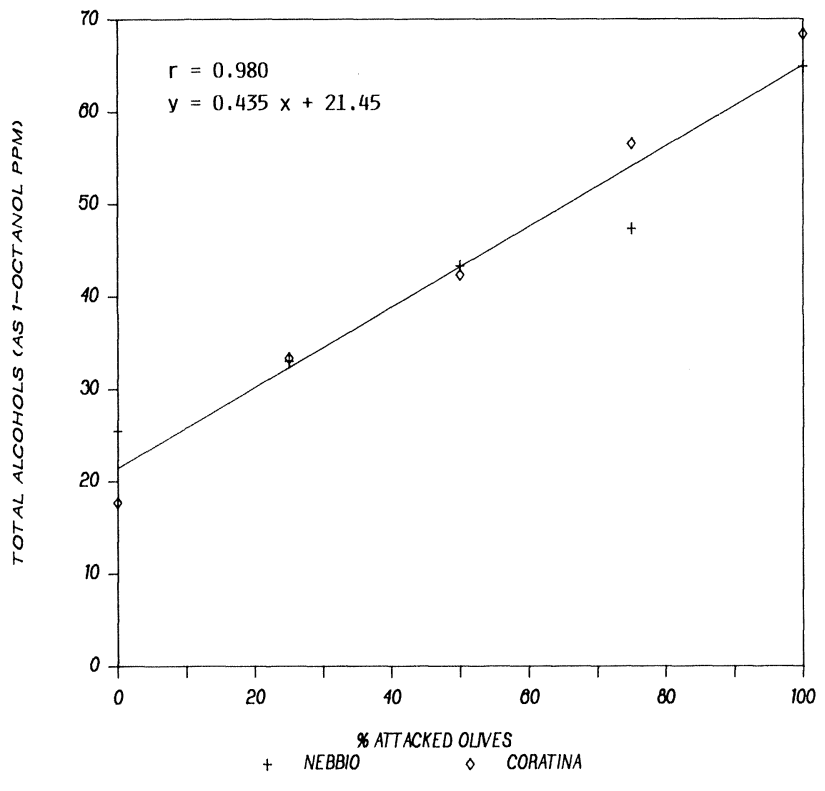

Figure 5.

Regression straight relative to the correlation between total alcohol contents and infestation extent for the oils obtained from both the examined varieties. 
The total alcohols, that were present in the modest quantities in the oils obtained from healthy olives, increase significantly in both the varieties, involving a worsening of the qualitative level of the oils as the percentage of infested olives grows. Moreover that total alcohol quantities for both the varieties are approximately equal and suffer the same increment with the increase in the percentage of infested olives giving well correlated results, according to the regression straight illustrated in Fig. 5 .

\subsection{Phenolic substances}

Fig. 6 represents the chromatograms of the phenolic substances of the oils obtained from the Coratina olive variety at differing percentages of infestation; Tab. $V$ shows the contents of polyphenols expressed in ppm of all the samples examined.
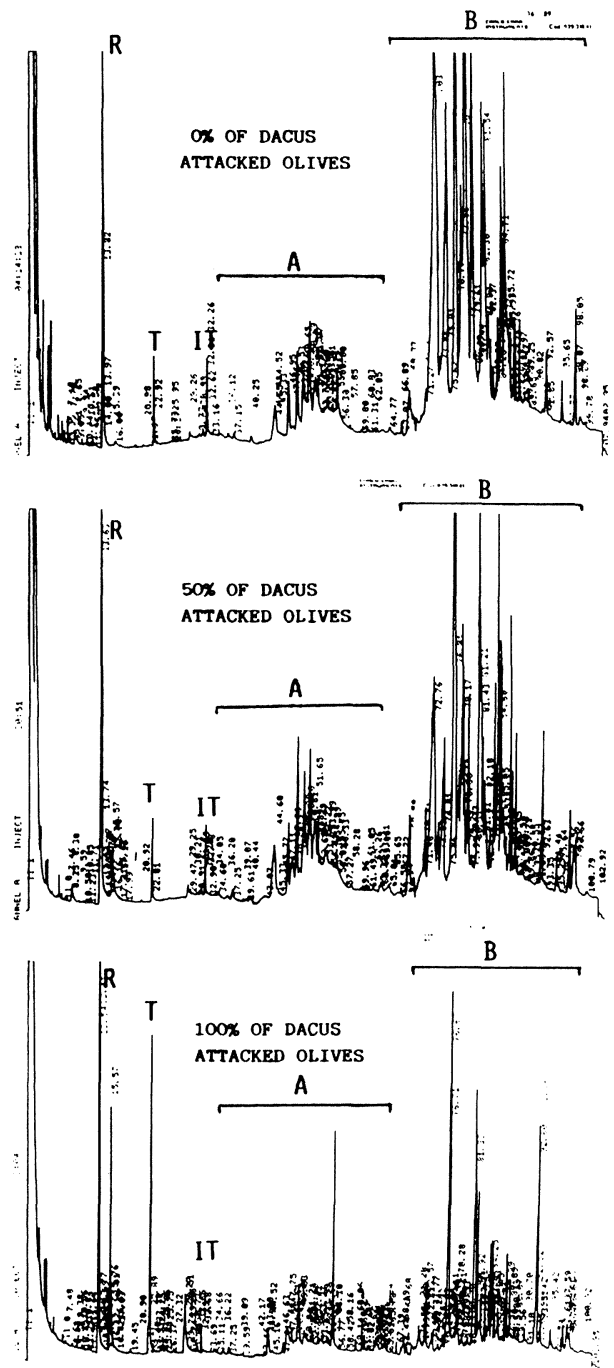

Figure 6

HRGC chromatograms of the phenolic substances of the oils obtained from Coratina variety at different percentage of attacked olives.

$R=$ resorcinol; $T$ = 4-hydroxy phenyl ethyl alcohol; $I T=3$, 4-dihydroxy phenyl ethyl alcohol; $A=$ simple phenols, probably derivatives of coumaric acid; $B=$ complex polyphenols (esters and polymers).
Table V

Content in ppm of phenolic substances of the oils obtained from Coratina and Nebbio varieties at different percentage of attacked olives. Such substances are identified with the same peak symbols of those in Fig. 6.

\begin{tabular}{lrrrrrr}
\hline Variety & $\begin{array}{c}\text { Attack } \\
\text { degree } \%\end{array}$ & T & IT & A & B $\begin{array}{c}\text { Total } \\
\text { phenolic } \\
\text { substances }\end{array}$ \\
\hline Coratina & $0 \%$ & 2,6 & 1,6 & 88,0 & 824,2 & 916,4 \\
Coratina & $25 \%$ & 3,2 & 10,6 & 142,6 & 583,8 & 740,2 \\
Coratina & $50 \%$ & 1,5 & 1,1 & 76,9 & 495,7 & 575,2 \\
Coratina & $75 \%$ & 1,6 & 1,2 & 110,3 & 314,7 & 427,8 \\
Coratina & $100 \%$ & 11,0 & 0,8 & 30,3 & 253,9 & 296,0 \\
Nebbio & $0 \%$ & 2,1 & 7,8 & 315,6 & 465,8 & 791,3 \\
Nebbio & $25 \%$ & 2,5 & 9,9 & 236,2 & 370,7 & 619,3 \\
Nebbio & $50 \%$ & 1,3 & 0,9 & 115,3 & 307,9 & 425,4 \\
Nebbio & $75 \%$ & 2,2 & 1,6 & 121,0 & 123,4 & 248,2 \\
Nebbio & $100 \%$ & 2,7 & 3,9 & 25,7 & 22,8 & 55,1 \\
\hline
\end{tabular}

From an examination of the data in the table, it appears evident, for both the varieties, that the total phenolic substances fall with the increment of the percentage of infested olives. These two parameters are perfectly correlated between them in a linear manner according to the regression straights illustrated in Fig. 7 that present different angular coefficients.

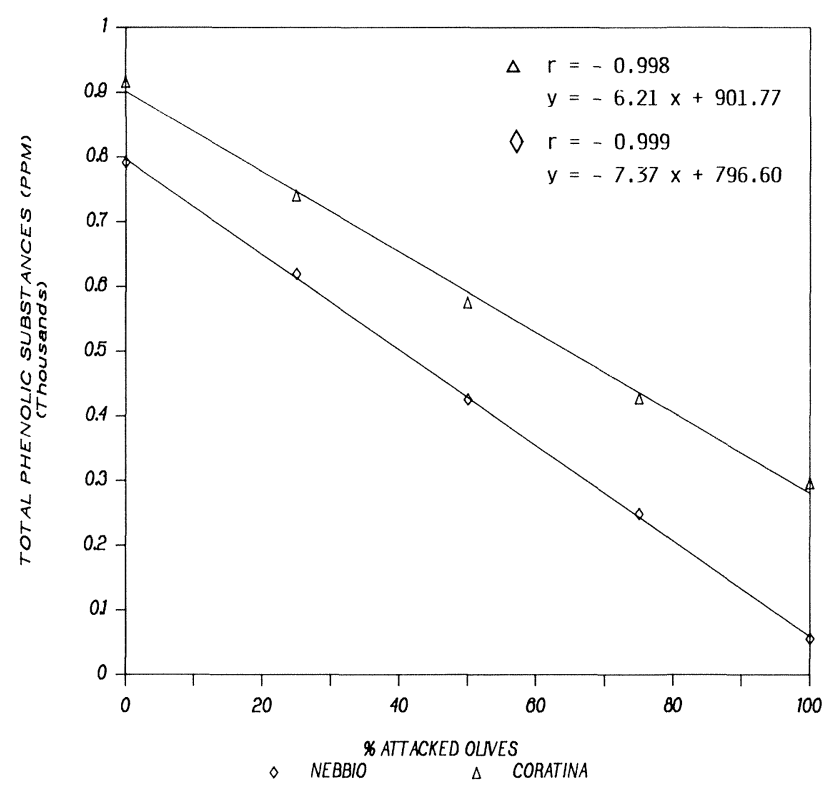

Figure 7

Regression straights relative to the correlation between infestation exten and total phenolic substances quantities for the oils obtained from both the examined varieties. 
The greater inclination verified for the Nebbio variety oils nevertheless finds a fairly simple explanation: in fact, while for the Coratina the reductions recorded are to be attributed esclusively to the Dacus attack, in the case of the Nebbio the decreases are a result also of the already cited fustiness.

From the complete analysis of all the analytical data taken into consideration it is to be concluded that the attack of $D$. Oleae on olives picked from the tree and quickly taken to extraction, does not produce, at least for levels of infestation up to $50 \%$, big variations of those parameters -organoleptic evaluation, acidity, number of peroxides, Kreiss reaction, U.V. spectrophotometry- up to now utilized for the trade classification of the oils. The declassing to virgin, determined from the sensorial evaluation, is evidenced in fact for the Coratina only when the levels of infestation are above $50 \%$, while in the case of the Nebbio it is already recorded on the sample obtained from $50 \%$ of infested olives of which the organoleptic evaluation has been also conditioned by the perception of fustiness.

Moreover, observing attentively the data that has resulted from the analyses that define the flavour, it is realized that the Dacus infestation determines substantial modifications of the volatile costituents.

The damage of the cellular structure of the olive caused by Dacus evidently actives enzymatic mechanisms -conversion of certain aminoacids into aldehydes and/or into corresponding alcohols (16), interconversion between aldehydes and corresponding alcohols (17), fermentation of the sugars, oxidation of unsaturated fatty acids (18)that had as a consequence the great trans-2-hexenal increase, notable production of carbonyl compounds with an unpleasant sensation and the considerable increase of volatile alcohols.

The chemical auto-oxidation of the unsaturated fatty acids would seem, though, to be greatly opposed from the antioxiding action of the phenolic substances that suffer a sharp decrease with the rise of infested olive percentage. This is confirmed by the modest increase that is recorded for the number of peroxides. The slight increase could be however, in part attributable to the presence of quinones formed from the oxidation of the phenolic substances, that go to interferring with the dosage of the same peroxides (19).

To sum up, the major contents of the volatile alcohols, of aldehydes with unpleasant sensation, the lower concentration of phenolic substances observed on the oils coming from infested olives, contribute towards determining a worsening of the qualitative level, also verified by the Panel and to comprimising the conservability.

Moreover it is of particular interest that the ratio, shown in Tab. VI, between the quantity of hexanal -the carbonyl compound more representative amongst those with an unpleasant sensation- and the alcohol quantity. This ratio, in fact, having been well correlated with the extent of infestation according to the regression straight illustrated in Fig. 8, enables one to determine in an objective way if and how much the olives from which comes oil has suffered a Dacus attack.



Regression straight relative to the correlation between hexanal/total alcohols ratio and infestation extent for the oils obtained from both the examined varieties.

Table VI

Hexanal/Volatile total alcohols ratio of the oils obtained from Coratina and Nebbio varieties at different percentage of attacked olives.

\begin{tabular}{ccccc}
\hline Variely & $\begin{array}{c}\text { Attack } \\
\text { degree }\end{array}$ & $\begin{array}{c}\text { Hexanal } \\
\text { (as undecanal } \\
\text { ppm) }\end{array}$ & $\begin{array}{c}\text { Total alcohols } \\
\text { (as 1-cclanol ppm) }\end{array}$ & $\begin{array}{c}\text { Hexanal } \\
\text { Total alcohols }\end{array}$ \\
\hline Coratina & $0 \%$ & 529,4 & 17,7 & 29,9 \\
Coratina & $25 \%$ & $1.134,8$ & 33,3 & 34,1 \\
Coratina & $50 \%$ & $1.707,6$ & 42,3 & 40,4 \\
Coratina & $75 \%$ & $2.522,0$ & 56,5 & 44,6 \\
Coratina & $100 \%$ & $3.964,0$ & 68,4 & 58,0 \\
Nebbio & $0 \%$ & 668,4 & 25,5 & 26,2 \\
Nebbio & $25 \%$ & $1.083,6$ & 33,0 & 32,8 \\
Nebbio & $50 \%$ & $1.692,7$ & 43,3 & 39,1 \\
Nebbio & $75 \%$ & $2.175,8$ & 47,3 & 46,0 \\
Nebbio & $100 \%$ & $3.248,8$ & 64,9 & 50,1 \\
\hline
\end{tabular}

For the purpose of verifying the validity of these results, six samples of oil obtained, with the same ways of extraction already described, from healthy olives Leccino, Moraiolo, Ghiacciole and Canino- and from olives at different levels of infestation -Ogliarola Salentina $(40 \%)$ and Coratina cultived in Puglia (20\%)- were subjected to HPLC analyses of volatile carbonyl compounds and alcohols.

The data obtained are shown in Tab. VII; for the first four samples the hexanal/total alcohols ratio always falls below the intercept of the equation that describes the regression straight in Fig. 8, while for the other two, this ratio corresponds to values of infestation of $44 \%$ and $19 \%$ respectively, which are in good agreement with the real extent of the Dacus attack. 
Table VII

Hexanal/Volatile total alcohols ratio and estimated infestation degree of some virgin olive oils employed as tests.

\begin{tabular}{lccccc}
\hline Variety & $\begin{array}{c}\text { Attack } \\
\text { degree }\end{array}$ & $\begin{array}{c}\text { Hexanal } \\
\text { (as undecanal } \\
\text { ppm) }\end{array}$ & $\begin{array}{c}\text { Total alcohols } \\
\text { (as 1-octanol } \\
\text { ppm) }\end{array}$ & $\begin{array}{c}\text { Hexanal } \\
\text { Total } \\
\text { alcohols }\end{array}$ & $\begin{array}{c}\text { Expected } \\
\text { attack } \\
\text { degree }\end{array}$ \\
\hline Leccino & $0 \%$ & 170,9 & 10,5 & 16,3 & $0 \%$ \\
Moraiolo & $0 \%$ & 120,4 & 11,0 & 10,9 & $0 \%$ \\
Ghiacciole & $0 \%$ & 227,1 & 24,2 & 9,4 & $0 \%$ \\
Canino & $0 \%$ & 369,8 & 17,3 & 21,4 & $0 \%$ \\
Ogliarola & & & & & \\
Salentina & $40 \%$ & 681,0 & 17,9 & 38,0 & $44 \%$ \\
Coratina & $20 \%$ & 445,7 & 13,7 & 32,5 & $19 \%$ \\
\hline
\end{tabular}

\section{CONCLUSIONS}

The analyses -organoleptic evaluation, acidity, number of peroxides, U.V. spectrophotometry, volatile compounds at $37^{\circ} \mathrm{C}$, phenolic substances- carried out on samples of oil obtained from the Coratina and Nebbio olive varieties at different levels of infestation, put into evidence that the increase in the extent of the Dacus attack has the following consequences:

- the Panel registers a slight but significant qualitative worsening of the oils;

- the free acidity, the number of peroxides and the specific absorption values in the U.V. increase progressively without nevertheless causing the declassing of the same oils;

- the phenolic substances decrease rapidly, compromising the conservability of the resulting oils;

- the trans-2-hexenal, the hexanal and the total carbonyl compounds increase sensitively and at the same time the 2-hexenal/hexanal ratio decreases implying a worsening of the oil quality;

- the quantity of the total alcohols modest for oils obtained from healthy olives, increases notably; in particular the increment of isoamyl alcohol leads one to suppose that the olives attacked by the Dacus suffer, once picked from the tree, those fermentation processes typical of fustiness, more rapidly that healthy olives;

- the hexanal/total alcohols ratio has a good correlation with the extent of infestation, so that it could be considered an objective element to establishing if and how much the olives from which oil is extracted have suffered a Dacus attack.

\section{ACKNOWLEDGMENTS}

Sincere thanks are extended to Dr. C. Basti for her precious collaboration given in supervising the infestation in the field and P.A.A. Serraiocco for this technical assistance offered in the execution of the analyses of the phenolic substances.

\section{BIBLIOGRAPHY}

1. Solinas, M.; Angerosa, F. (1989).- "Nouveaux indices de qualité de I'huile d'olive vierge".- 'Chevreul' International Congress Acts.- Angers 6/9 June 1989.

2. Consiglio Oleicolo Internazionale.- COI/T.20/Doc. n. 318-6/1987.

3. Solinas, M.; Angerosa, F. (1984-87).- "Influenza del tempo di stoccaggio delle olive destinate all'estrazione sull'aroma degli oli di risulta".- Ann. Ist. Sper. Elaiot. X.

4. Angerosa, F.; Solinas, M.; Di Giacinto, L. (1989).- "Influence du stockage des olives sur la flaveur de l'huile".- 'Chevreul' International Congress Acts.- Angers 6/9 June 1989.

5. Angerosa, F.; Di Giacinto, L.; Solinas, M. (1990).- "Influenza dello stoccaggio in massa delle olive sull'aroma degli oli di risulta: valutazione del difetto di 'riscaldo' mediante analisi HPLC e GLC de componenti volatili". - Riv. Merceol. 29, 275-294.

6. Andrich, G.; Pisanelli, A.; Fiorentini, R.; Belcari, A.; Quaglia, F. (1985)."Influenza dell'infestazione dacica sulla composizione delle olive e sulle caratteristiche degli oli di estrazione".- Riv. Ital. Sostanze Grasse 62, 209-211.

7. Parlati, M.V.; Petruccioli, G.; Turco, D. (1981/83).- “Effetti dell'attacco del 'Dacus' sulla qualità dell'olio".- Ann. Ist. Sper. Olivicoltura Cosenza VII.

8. Parlati, M.V.: Petruccioli, G.; Pandolfi, S. (1989).- "Effects of the Dacus infestation on the oil quality".- Proceeding International symposium quality on olive growing.- Córdoba 2/5 October 1989.

9. Montedoro, G.; Garofolo, L.; Sensidoni, A. (1985).- "Infestione di olive da Dacus oleae e caratteristiche qualitative degli oli vergini".Riv. Ital. Sostanze Grasse 62, 565-567.

10. Solinas, M.; Angerosa, F., Cucurachi, A. (1987).- "Connessione tra prodotti di neoformazione ossidativa delle sostanze grasse $e$ insorgenza del difetto di rancidità all'esame organolettico. Nota 2. determinazione quantitativa".- Riv. Ital. Sostanze Grasse 64, 137-145.

11. Solinas, M.; Marsilio, V.; Angerosa, F. (1987).- "Evoluzione di alcun componenti dell'aroma degli oli vergini di oliva in relazione al grado $\mathrm{d}$ maturazione delle olive".- Riv. Ital. Sostanze Grasse 64, 475-480.

12. Solinas, M. (1987).- "Analisi HRGC delle sostanze fenoliche di oll vergini di oliva in relazione al grado di maturazione e alla varietá delle olive".- Riv. Ital. Sostanze Grasse 64, 255-262.

13. Camera, L.; Solinas, M. (1990).- "Identificazione di alcune sostanze aromatiche degli oli di oliva mediante GLC-MS". - International Seminar Acts "Olio di oliva e olive da tavola: tecnologia e qualità".- Città S. Angelo 25/28 April 1990, 153-168.

14. Flath, A.R.; Forrey, R.R.; Guadagni, D.G. (1973).- "Aroma components of olive oil".- J. Agric. Food Chem. 21, 948-952.

15. Bertuccioli, M.; Anichini, F.; Montedoro, G. (1978).- "Maturazione delle olive e qualità dell'olio: costituenti volatili dello 'spazio di testa'".Tecnol. Alim. mar/apr, 97-109.

16. Drawert, F.; Rapp, A. und Ullemeyer, H. (1967).- "Radio gaschromatographische Untersuchung der Stoff wechselleistungen von Hefen (Saccharomyces und Schizosaccharomyces) in der Bildung von Aromastoffen".- Vitis 6, 177-197.

17. Eriksson, C.E. (1968).- "Alcohol: NAD Oxidoreductase (E.C. 1.1.1.1.) from peas".- J. Food Sci. 33, 525-532.

18. Hatanaka, A.; Kajiwara, T. and Sekiya, J. (1987).- "Biosynthetic pathway for $\mathrm{C}_{6}$-aldehydes formation from linolenic acid in green leaves".Chem. Phys. Lipids 44, 341-361.

19. Montedoro, G. (1973).- "Esame analitico dei costituenti fenolici present nell'olio di oliva in funzione delle caratteristiche della drupa, loro ruolo nella stabilità all'ossidazione e possibile interferenza nella determinazione del numero dei perossidi".- Ann. Fac. Agraria Perugia 28, 99-116.

(Recibido: Agosto 1991) 